\title{
Activity Preferences Among Older People With Dementia Residing in Nursing Homes
}

\author{
Eun-Young Park ${ }^{1}$ and Jung-Hee Kim ${ }^{2 *}$ \\ ${ }^{1}$ Department of Secondary Special Education, College of Education, Jeonju University, Jeonju, South Korea, ${ }^{2}$ College \\ of Nursing, The Catholic University of Korea, Seoul, South Korea
}

The study aimed to examine the influence of personal characteristics on activity preferences using decision tree analysis and examine the effects of the variables using conventional approaches (logistic regression analysis). A descriptive study was conducted with 251 nursing home residents with dementia in Korea (76.9\% female) to examine the relationship between their personal characteristics and activity preferences. Decision tree analysis was used to classify participants' activity preferences, and preference levels were examined using logistic regression analysis. Activities were classified as either physical and social activities or cognitive and affective activities. This model showed an accuracy rate of $85.7 \%$ for positively predicting physical and social

OPEN ACCESS

Edited by:

David Facal,

University of Santiago de Compostela, Spain

Reviewed by:

Carlos Dosil,

University of Santiago de Compostela, Spain

Fabrizio Stasolla,

Giustino Fortunato University, Italy

*Correspondence: Jung-Hee Kim

jhee90@catholic.ac.kr

Specialty section:

This article was submitted to Psychology of Aging, a section of the journal Frontiers in Psychology

Received: 22 October 2021 Accepted: 10 December 2021 Published: 20 January 2022

Citation:

Park E-Y and Kim J-H (2022) Activity Preferences Among Older People With Dementia Residing in Nursing Homes.

Front. Psychol. 12:799810. doi: 10.3389/fpsyg.2021.799810 activity preference and $30.3 \%$ for positively predicting cognitive and affective activity preference. Gender was the strongest determinant of activity preference. The odds of preferring physical and social activities were 3.179 times higher among women, while the odds for preferring cognitive and affective activities were 0.412 times higher among men. Notably, cognitive and affective activity preference increased to 58.8\% for married male participants. This study's findings can contribute to the development of programs to decrease behavioral and psychological symptoms among older people with dementia residing in nursing homes and provide scientific evidence for integrating these activities into long-term services for this population.

Keywords: decision tree, older people, dementia, nursing homes, activity preferences

\section{INTRODUCTION}

A major problem related to dementia is cognitive decline, which makes it difficult for people to maintain their usual activities (Nygård, 2004; Van Der Roest et al., 2007; O'Sullivan and Hocking, 2013). People with dementia tend to be less involved in leisure activities due to the loss of their physical and cognitive abilities, which could lead to feeling isolated from friends and family, depressive mood, and boredom (Engelman et al., 1999; Feliciano et al., 2009). In particular, boredom and loneliness are common among people with dementia who reside in nursing homes (Cohen-Mansfield et al., 1992, 2017). Several studies have reported that environmental stimuli can increase behavioral and psychological symptoms and decrease positive affect among people with dementia (Cohen-Mansfield and Werner, 1997; Cohen-Mansfield et al., 2010a, 2011). Further, various activities, including physical activities, have the potential to improve the quality of life of people with severe mental health disorders (Richardson et al., 2005b).

Patients with dementia prefer positive stimuli and close social relationships over superficial encounters with institutional staff during their daily treatment (Mark, 2012). Socioemotional 
selectivity is a theory of life-span development grounded in the uniquely human ability to monitor time. The preferences, social networks, and emotional experiences of patients with dementia could be informed by the theory of life-span development. The emphasis on individual strengths and personal resilience is likely to be especially appealing to older people (Carstensen, 2021). Patients with cognitive impairments also have normal human psychological needs, including comfort, identity, attachment, occupation, and inclusion (Kitwood, 1997). Strategies for accessing the internal experiences of patients with dementia may be useful to understand them as individuals. However, only limited knowledge is available about the experience of those with dementia due to the deleterious effects of the stereotypes regarding individuals afflicted with it (Mast, 2009).

Both personal and group activities, including those involving families, have been found to be important for people with dementia (Chester et al., 2018; Roberts et al., 2018). Moreover, maintaining social contact and participating in family activities could increase older people's life satisfaction and self-esteem and their perception of having continuity across their life course (Vikström et al., 2008; Cruz et al., 2013; Jøranson et al., 2016; Olsen et al., 2019). Physical activity interventions for those with mental health disorders must be tailored to individual preferences, which can also be beneficial for leisure and activities of daily living (Richardson et al., 2005a). For patients with dementia, activity is perceived as important, and while personcentered approaches are expected to contribute to activity promotion, individualized activities are often not provided for these patients (Van't Leven et al., 2018).

According to Cohen-Mansfield et al. (2017), contributing factors that affect activity participation can be categorized as personal, environmental, or stimulus. Dementia patients' endorsed activities were affected by gender and physical or cognitive function. Individualized support should be provided considering personal preferences and characteristics, such as stage of dementia, physical function, and health status (Ablitt et al., 2009; Peeters et al., 2010; Van Mierlo et al., 2010). These activity preferences were also affected by other personal factors, such as past experiences (Cohen-Mansfield, 2017). In addition, patients' needs may be impacted by culture, and health care professionals need to show continuous cultural sensitivity to patients' needs. This information is important for planning activities and intervention programs that are closely related to endorsement of or engagement in activities. However, few studies have examined the activity preferences of older people with dementia residing in nursing homes. Decision trees based on real-word data have been used to create rules for activity preferences, as they can detect previously unknown interactions among various items of clinical information and reveal relationships between assessment outcomes and patient characteristics. This technique can identify data patterns that distinguish between preferred activities and other activities, revealing potentially complex relationships among individual characteristics (Myles et al., 2004).

A preference assessment could guide health care professionals in providing reinforcements to patients to increase the future probability of a behavior. A preference assessment is defined as a process to identify reinforcers that will motivate an individual at a specific point in time (Chen and Chen, 2005). Identifying factors that may function as positive stimuli and environments is important, as results of previous research indicate that a tailored intervention is more efficacious than treating patients as a homogenous group (Vollmer et al., 1994). Although there is a substantial need to assess activity preferences among patients with dementia, limited cognition and a lack of verbal responsiveness can be barriers to fully discerning their preferences (Mast, 2009).

This descriptive study examined personal characteristics within the context of preferred activities among nursing home residents with dementia. The study aimed to examine the influence of personal characteristics on activity preferences using decision tree analysis and examine the effects of the variables using conventional approaches (logistic regression analysis).

\section{METHODS}

A secondary analysis was conducted that aimed to identify the activity preferences of older people with dementia residing in nursing homes in Korea.

\section{Data}

The source of the data was a large-scale research project which focused on the behavioral and psychological symptoms of patients with dementia to develop an intervention program to improve their quality of life. The project obtained approval from the Institutional Review Board of Catholic University of Korea (MC18QNSI0055). Details of the sampling process have been reported elsewhere (Park et al., 2019). Data were collected from six nursing homes selected at random in the Seoul and Gyeonggi regions of Korea after explaining the purpose of the study and obtaining approval from the directors and nurse managers. Participants were recruited by an ad posted in the approved facilities for 2 weeks, and patients willing to participate in the study who met inclusion criteria were selected. When older people with dementia expressed their willingness to participate, a mental health expert at the facility confirmed the patient's ability to consent. If they agreed, the researchers then contacted the participants and their legal guardians to obtain written consent.

The researchers surveyed the patients in person upon consent from the patient and their family. The inclusion criteria were being 65 years of age or older with a diagnosis of dementia, a resident or daycare visitor with dementia, and ability to respond to questions about activity preferences. The exclusion criteria included having other mental disorders, neurological disorders, or metabolic disorders. Among the 325 recruited participants, 70 participants who either did not report preferred activities or whose caregivers did not report such activities on their behalf were excluded. Only 4 participants were excluded due to having another diagnosed mental disorder. Ultimately, 251 participants were included and 74 participants were excluded from the study.

The minimum data size required for classification matrix research using data mining is calculated as follows: $6 \times$ number of groups for the output variable $\times$ number of variables 
(Delmater and Hancock, 2001). For the number of groups for the output variable, the preferred activities among patients with dementia were classified into two types, and there were seven variables (gender, age, education level, marital status, religion, use of assistive devices, and ability for self-expression), which resulted in a minimum data size of 140 .

\section{Data Collection}

Data were collected by trained researchers from medical records or by interviewing patients with dementia regarding gender, age, education level, marital status, religion, use of assistive devices, and ability for self-expression. To examine patients' preferred activities, an open-ended question was used: "What kind of activities do you like to do?" If the patients could not answer the question, their caregiver, who had provided care for the patient for at least 4 weeks, answered for them as a proxy. The question about the ability to express one's opinions to others was also answered by the caregiver if the patient could not answer. A trained researcher asked the patients the questions directly using a structured questionnaire and recorded their responses.

The recorded activities were classified according to the criteria described below. Activities such as taking a stroll, participating in activities offered at the facility, talking to people, participating in religious activities, meeting with family, and talking to someone on the telephone were classified as physical and social activities (activities usually involving other people). Activities such as

TABLE 1 | Characteristics of patients with dementia $(n=251)$.

\begin{tabular}{|c|c|c|}
\hline Characteristics & $\mathbf{n}$ & $\%$ \\
\hline \multicolumn{3}{|l|}{ Gender } \\
\hline Male & 57 & 22.7 \\
\hline Female & 193 & 76.9 \\
\hline Missing & 1 & 0.4 \\
\hline \multicolumn{3}{|l|}{ Age } \\
\hline Below 84 & 122 & 48.6 \\
\hline Above 85 & 124 & 49.4 \\
\hline Missing & 5 & 2.0 \\
\hline \multicolumn{3}{|l|}{ Presence of spouse } \\
\hline Yes & 69 & 27.5 \\
\hline No & 182 & 72.5 \\
\hline \multicolumn{3}{|l|}{ Religion } \\
\hline Yes & 66 & 26.3 \\
\hline No & 185 & 73.7 \\
\hline \multicolumn{3}{|l|}{ Education level } \\
\hline Below middle school & 148 & 59.0 \\
\hline Above middle school & 90 & 35.9 \\
\hline Missing data & 13 & 5.2 \\
\hline \multicolumn{3}{|c|}{ Use of assistive device } \\
\hline No & 184 & 73.3 \\
\hline Yes & 57 & 22.7 \\
\hline Missing data & 10 & 4.0 \\
\hline \multicolumn{3}{|c|}{ Degree of self-expression } \\
\hline High & 160 & 63.7 \\
\hline Low & 79 & 31.5 \\
\hline Missing data & 12 & 4.8 \\
\hline
\end{tabular}

watching television, playing traditional games, doing puzzles, reading picture books, drawing, and singing were classified as cognitive and affective activities (activities usually performed alone). Two independent researchers (A and $\mathrm{B}$ ) performed the classification.

\section{Statistical Analysis}

A decision tree analysis was performed in this study. A decision tree is a data mining technique that explores, identifies, and models relationships, patterns, and rules within a dataset. Decision tree analysis graphs decision-making rules in a treelike structure and performs classification and prediction. One of the benefits of decision tree analysis is that it expresses the processes of classification and prediction through induction rules according to the tree structure; thus, it is easier for the user to understand these processes compared to neural network analysis, discriminant analysis, or regression analysis (Kim et al., 2006). A decision tree can be used to identify the variables needed for analyses, such as discriminant analysis or regression analysis, and the interaction effects to be included in the model, and a decision tree itself can be used as a classification or predictive model (Ablitt et al., 2009). A decision tree features a tree structure consisting of nodes.

Decision tree analysis was performed according to the following steps. First, a tree structure was formulated by designating the appropriate split criterion and stopping rule according to the purpose of the analysis and data structure. In this study, as the target attribute was discrete, splitting occurred based on the frequency of data for each category of the target attribute, based on which a classification tree was built. The stopping rule was set to maximum tree depth $=5$, minimum number of cases for parent node $=30$, and minimum number of cases for child node $=10$. To develop an ideal model using data mining, it is desirable to create various predictive models from a single dataset and comparatively analyze them (Song and Ying, 2015). Thus, the entire dataset was divided into training data and test data, and a model was created using the training data and verified using the test data. Hence, in this study, the ratio of training data to test data was set to $1: 1$.

For the decision tree analysis, the most universally used Classification and Regression Trees (1984; CART) algorithm was applied. The relationships between the characteristics of patients with dementia and their activity preferences were analyzed using logistic regression. SPSS 25.0 software was used for statistical analysis.

The dependent variable was the preferred activity, and it was divided into physical and social activities and cognitive and affective activities for analysis. Predictors could be divided into (a) demographic characteristics and (b) ability outcomes. Demographic characteristics included gender, age, education level, marital status, and religion, and ability outcomes included the use of assistive devices for mobility and ability for selfexpression, defined as the ability to express one's opinions to others. Marital status was recorded as either married or not married. Individuals were considered not married if they were widowed, single, or divorced. Religion was coded as either "yes" 
Physical, social activity

\begin{tabular}{|lrr|}
\hline \multicolumn{3}{|c|}{ Node 0 } \\
& $\%$ & n \\
\hline Not preferred & 36.9 & 45 \\
Preferred & 63.1 & 77 \\
\hline Total & 100.0 & 122 \\
\hline & \multicolumn{2}{c}{} \\
& Gender
\end{tabular}

Adj. $p$-value $<0.001$,

Chi-square $=10.364, \mathrm{df}=1$

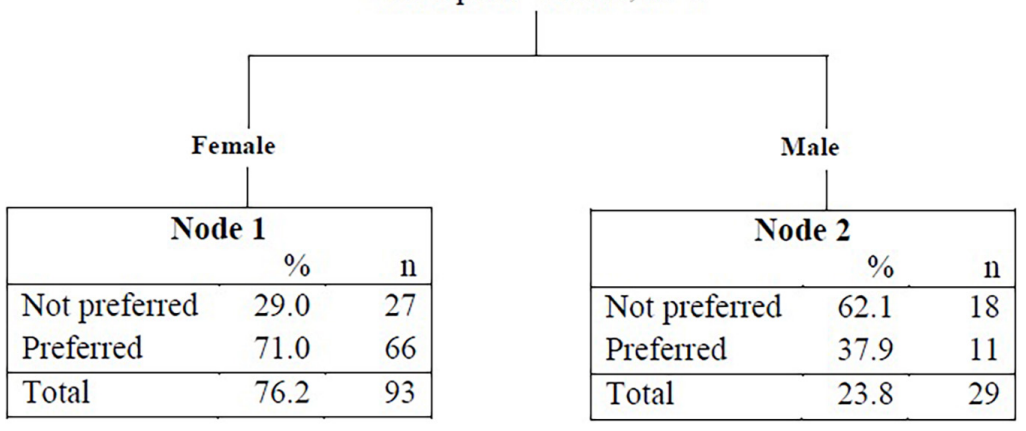

FIGURE 1 | Decision tree for predicting physical and social preference.

or "no," and the use of assistive devices for mobility referred to the use of devices such as crutches, wheelchairs, or canes.

\section{RESULTS}

\section{Participant Characteristics}

A total of 251 participants were included in the analysis. The sample was $76.9 \%$ female and $22.7 \%$ male, and $49.4 \%$ were aged 85 years or older. Of the participants, $72.5 \%$ were not married and $26.3 \%$ were religious. The most common education level was middle school graduation or lower (59.0\%), and $22.7 \%$ of the participants used an assistive device for mobility. Each participant's level of self-expression was recorded as either high (63.7\%) or low (31.5\%) (Table 1).

\section{Predictors of Physical and Social Activity Preference}

The results of the decision tree used to predict physical and social activity preference among participants are illustrated in Figure 1. The strongest discriminant of physical and social activity preference was patient gender. Specifically, $63.1 \%$ of the entire sample preferred physical and social activities; however, when participants were stratified by gender, this increased to $71.0 \%$ for female participants and decreased to $37.9 \%$ for male participants (Figure 1).

This model showed an accuracy rate of $40.0 \%$ for predicting those who did not prefer physical and social activities (18 out of 45 patients) and an accuracy rate of $85.7 \%$ for predicting those who did prefer physical and social activities (66 out of 77) (Table 2). The influence of patient characteristics such as gender, age, education level, marital status, self-expression, use of assistive devices, religion, and children are shown in Table 3. Gender was identified as a significant predictor of physical and social activity preference $[B=1.157$, S.E. $=0.388, \operatorname{Exp}(\beta)=3.179$, $p=0.003]$. The odds of preferring physical and social activities were 3.179 times higher among women than men.

\section{Predictors of Cognitive and Affective Activity Preference}

The results of the decision tree for predicting cognitive and affective activity preference are illustrated in Figure 2. The most potent discriminant of cognitive and affective activity preference was patient gender. Specifically, $25.4 \%$ of the entire sample preferred cognitive and affective activities; however, when stratified by gender, this decreased to $19.6 \%$ for female participants and increased to $42.4 \%$ for male participants. The second discriminant was marital status. The

\begin{tabular}{|c|c|c|c|c|c|c|}
\hline \multicolumn{2}{|c|}{ Classification matrix } & \multicolumn{3}{|c|}{ Prediction } & \multicolumn{2}{|c|}{ Forecasting } \\
\hline & & $\begin{array}{c}\text { Not } \\
\text { preferred }\end{array}$ & Preferred & Total & $\begin{array}{l}\text { Accuracy } \\
\text { measures }\end{array}$ & $\%$ \\
\hline \multirow[t]{3}{*}{$\begin{array}{l}\text { Training } \\
\text { data }\end{array}$} & $\begin{array}{c}\text { Not } \\
\text { preferred }\end{array}$ & 18 & 27 & 45 & Specificity & 40.0 \\
\hline & Preferred & 11 & 66 & 77 & Sensitivity & 85.7 \\
\hline & Total & 29 & 93 & 122 & $\begin{array}{c}\text { Overall } \\
\text { accuracy }\end{array}$ & 68.9 \\
\hline
\end{tabular}

CHAID, Chi-squared automatic interaction detection. 
preference for cognitive and affective activity increased to $58.8 \%$ among male participants with a spouse. This model showed an accuracy rate of $92.8 \%$ for predicting those who

TABLE 3 | Summary of logistic regression analysis for the preference of physical and social activities.

\begin{tabular}{lccccccc}
\hline Variable & B & S.E. & df & Exp $(\boldsymbol{\beta})$ & $\mathbf{- 9 5 \%} \mathbf{C l}$ & $\mathbf{+ 9 5 \%} \mathbf{C l}$ & $\boldsymbol{p}$ \\
\hline Gender $^{\mathrm{a}}$ & 1.16 & 0.39 & 1 & 3.18 & 1.49 & 6.80 & 0.003 \\
Age $^{\mathrm{b}}$ & -0.06 & 0.31 & 1 & 0.94 & 0.51 & 1.73 & 0.834 \\
Education level $^{\mathrm{C}}$ & -0.11 & 0.32 & 1 & 0.90 & 0.48 & 1.69 & 0.735 \\
Presence of spouse $^{\mathrm{d}}$ & -0.32 & 0.36 & 1 & 0.73 & 0.36 & 1.46 & 0.372 \\
Degree of self-expression $^{\mathrm{e}}$ & 0.37 & 0.33 & 1 & 1.45 & 0.76 & 2.76 & 0.261 \\
Use of assistive device $^{f}$ & -0.65 & 0.34 & 1 & 0.52 & 0.27 & 1.02 & 0.056 \\
Religiong $_{\text {Children }^{\text {h }}}$ & -0.17 & 0.34 & 1 & 0.84 & 0.43 & 1.64 & 0.614 \\
& 1.51 & 0.83 & 1 & 4.54 & 0.90 & 22.99 & 0.068 \\
\hline
\end{tabular}

${ }^{a}$ Dummy variables (Reference $=$ female).

${ }^{b}$ Dummy variables (Ref $=$ above 85$)$.

${ }^{c}$ Dummy variables (Ref $=$ below middle school).

${ }^{d}$ Dummy variables $(\operatorname{Ref}=$ no) .

eDummy variables (Ref $=$ low).

${ }^{f}$ Dummy variables $($ Ref $=$ no).

${ }^{g}$ Dummy variables $($ Ref $=$ no).

${ }^{h}$ Dummy variables $(\operatorname{Ref}=$ no $)$. did not prefer cognitive and affective activity (90 out of 97) and an accuracy rate of $30.3 \%$ for predicting those who did prefer cognitive and affective activities (10 out of 33) (Table 4).

The influence of patient characteristics, such as gender, age, education level, marital status, self-expression, use of assistive device, religion, and children, on cognitive and affective activity preference are shown in Table 5. Gender $[B=-0.886$, S.E. $=0.405$, $\operatorname{Exp}(\beta)=0.412, p=0.029]$ and education level $[B=0.797$, S.E. $=0.354, \operatorname{Exp}(\beta)=2.219, p=0.024]$ were identified as significant predictors of cognitive and affective activity preference. The odds for preferring cognitive and affective activities were 0.412 times higher among men than women and 2.219 times higher among middle school graduates or higher than their less educated counterparts.

\section{DISCUSSION}

This study aimed to examine the influence of personal characteristics on activity preferences using decision tree analysis and examine the effects of personal characteristics using logistic regression analysis. Engaging in activities

Cognitive, affective activity

\begin{tabular}{|lrr|}
\hline \multicolumn{3}{|c|}{ Node 0 } \\
& \% & n \\
\hline Not preferred & 74.6 & 97 \\
Preferred & 25.4 & 33 \\
\hline Total & 100.0 & 130 \\
\hline & & \\
\hline
\end{tabular}

\section{Gender}

Adj. $p$-value $=0.009$,

Chi-square $=6.780, \mathrm{df}=1$
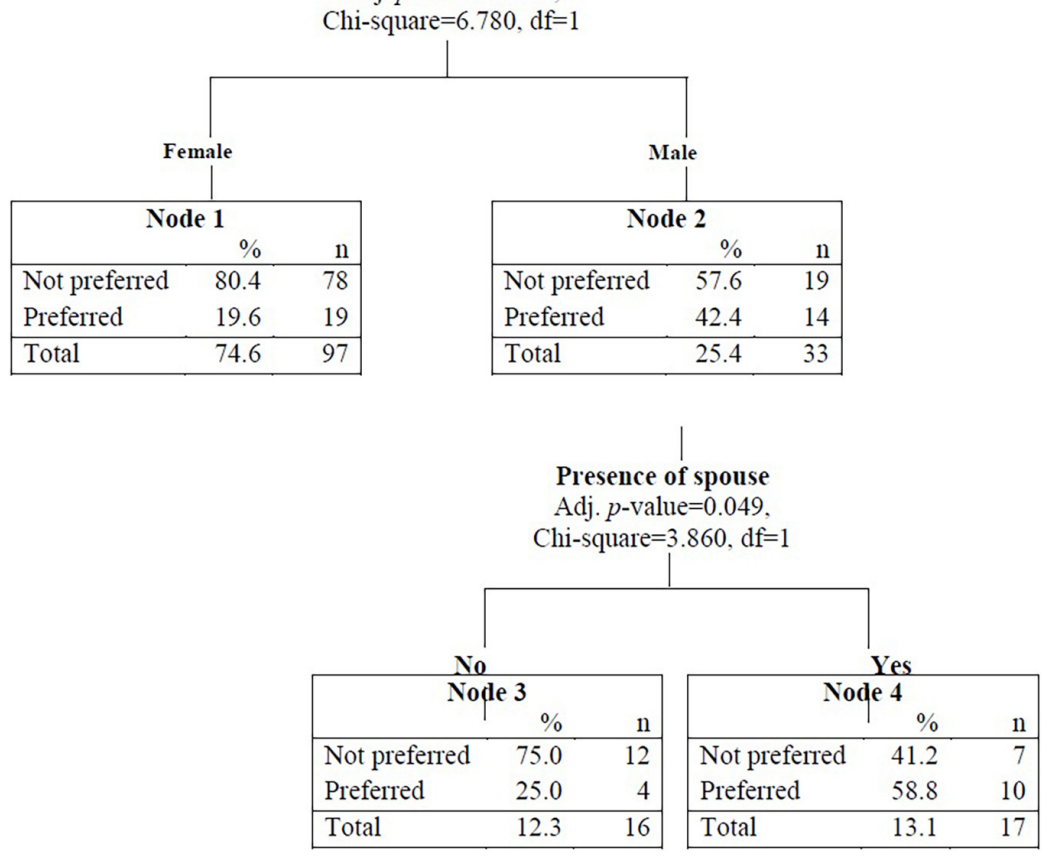

FIGURE 2 | Decision tree for predicting preference in cognitive and affective activities. 
TABLE 4 | Classification matrix of CHAID for cognitive and affective activities.

\begin{tabular}{|c|c|c|c|c|c|c|}
\hline \multicolumn{2}{|c|}{ Classification matrix } & \multicolumn{3}{|c|}{ Prediction } & \multicolumn{2}{|c|}{ Forecasting } \\
\hline & & $\begin{array}{c}\text { Not } \\
\text { preferred }\end{array}$ & Preferred & Total & $\begin{array}{l}\text { Accuracy } \\
\text { measures }\end{array}$ & $\%$ \\
\hline \multirow[t]{3}{*}{$\begin{array}{l}\text { Training } \\
\text { data }\end{array}$} & $\begin{array}{l}\text { Not } \\
\text { preferred }\end{array}$ & 90 & 7 & 97 & Specificity & 92.8 \\
\hline & Preferred & 23 & 10 & 33 & Sensitivity & 30.3 \\
\hline & Total & 113 & 17 & 120 & $\begin{array}{c}\text { Overall } \\
\text { accuracy }\end{array}$ & 76.9 \\
\hline
\end{tabular}

CHAID, Chi-squared automatic interaction detection.

TABLE 5 | Summary of logistic regression analysis for preference of cognitive and affective activities.

\begin{tabular}{lcccccccc}
\hline Variable & B & S.E. & df & Exp $(\boldsymbol{\beta})$ & $\mathbf{- 9 5 \%} \mathbf{C l}$ & $\mathbf{+ 9 5 \%} \mathbf{C l}$ & $\boldsymbol{p}$ \\
\hline Gender $^{\mathrm{a}}$ & -0.87 & 0.41 & 1 & 0.41 & 0.19 & 0.91 & 0.029 \\
Age $^{\mathrm{b}}$ & 0.51 & 0.36 & 1 & 1.66 & 0.82 & 3.36 & 0.160 \\
Education level $^{\mathrm{c}}$ & 0.80 & 0.35 & 1 & 2.22 & 1.11 & 4.44 & 0.024 \\
Presence of spouse $^{\mathrm{d}}$ & -0.30 & 0.38 & 1 & 0.74 & 0.36 & 1.55 & 0.425 \\
Degree of self-expression $^{\mathrm{e}}$ & 0.01 & 0.36 & 1 & 1.01 & 0.50 & 2.05 & 0.982 \\
Use of assistive device $^{\mathrm{f}}$ & -0.11 & 0.38 & 1 & 0.90 & 0.43 & 1.89 & 0.771 \\
Religion $^{\mathrm{g}}$ & 0.49 & 0.40 & 1 & 1.63 & 0.75 & 3.53 & 0.220 \\
Children $^{\mathrm{h}}$ & -0.16 & 0.76 & 1 & 0.86 & 0.19 & 3.76 & 0.835 \\
\hline
\end{tabular}

a Dummy variables (Reference $=$ female).

${ }^{b}$ Dummy variables (Ref $=$ above 85).

${ }^{c}$ Dummy variables (Ref $=$ below middle school).

${ }^{d}$ Dummy variables $(\operatorname{Ref}=$ no).

e Dummy variables (Ref $=$ low)

${ }^{f}$ Dummy variables (Ref $=$ no).

gDummy variables (Ref $=$ no).

${ }^{h}$ Dummy variables (Ref $=$ no).

alleviates boredom among patients with dementia residing in nursing homes and helps to evoke positive emotions (Cohen-Mansfield et al., 2010a, 2011).

The first predictor of activity preference was gender. In this study, older women were found to prefer physical and social activities, while older men were found to prefer cognitive and affective activities. Caregiving, which is typically considered to be a role for women, strengthens their interactions with others. Furthermore, women tend to be more relationshiporiented than men (Boyle, 2017), and thus seem to have demonstrated a higher preference for social activities. Other studies have documented that older women with dementia prefer cooking or baking (Menne et al., 2012; Cohen-Mansfield et al., 2019). Owing to the perception of traditional gender roles, in which women are expected to engage in housework and caregiving (Kyungsoon Park, 2018), activity preferences may differ between genders. Gender roles are learned over a prolonged period, and may therefore influence patients with dementia (Boyle, 2017). Further, older people with dementia have been reported to show consistent leisure activity preferences from the past to the present (Lepper et al., 2020) and more actively participate in activities when given a similar simulation to what they were used to in the past (Cohen-Mansfield et al., 2010b; Lopes et al., 2016). Thus, gender-specific activities should be planned for older people in nursing homes.
Despite the fact that men are traditionally seen as being engaged in physical labor (Kyungsoon Park, 2018), older men showed a low preference level for physical and social activities. This may be related to the characteristics of patients with dementia. In general, weakened physical functioning leads to patients with dementia being more sedentary than the general population, and studies have reported that walking, as opposed to more vigorous activities, is the most common physical activity among these patients (Daumit et al., 2005; Richardson et al., 2005b). Previous research reported that older women with dementia score various activities as more important than their male counterparts (Roberts et al., 2018), which supports our findings. A lack of periodic social contact is correlated with physical inactivity and lethargy (Daumit et al., 2005; McDevitt et al., 2006) and low selfefficacy (Trost et al., 2002). Thus, programs that promote physical and social activities in older men with dementia are also needed.

The higher preference for cognitive and affective activities among men in this study is similar to previous findings that men demonstrated a higher preference for games such as brain games (Ivory, 2006) and that older men like games (Menne et al., 2012; Cohen-Mansfield et al., 2019). A prior study also found that older men with dementia tend to be more individualistic and logical compared to their female counterparts (Boyle, 2017). Further, our results showed that the preference for cognitive and affective activities increased to $58.8 \%$ among older men with a spouse. According to Roberts et al. (2018), married individuals prefer activities such as bonding with family more than unmarried individuals; thus, continued attachment with a spouse seems to increase individuals' preferences for these activities.

Multiple regression analysis confirmed that the odds of preferring cognitive and affective activities were higher among more highly educated individuals when adjusting for age, marital status, ability for self-expression, use of assistive devices, religion, and children. Education level seems to have affect preference levels, as cognition-based activities stimulate overall cognitive function through games, maps, and discussions and include concentration, memory, and problem-solving ability training (Kim, 2019).

In this study, we determined the hierarchy of personal characteristics of activity preferences using decision tree analysis and the effects of personal characteristics using logistic regression analysis. There is a difference between the data mining tools used for classification and logistic regression analysis. The logistic regression model serves to determine which variables predict treatment status and contribute to predicting preferred activities (Chatterjee and Hadi, 2015). However, data mining algorithms find the best fitting model through automated processes that search through the dataset to detect patterns. These patterns may include interactions between variables, as well as interactions within subsets of variables (Linden and Yarnold, 2016).

This study examined the relationship between personal characteristics and activity preferences of patients with dementia. The results of this study provide evidence to support the need for patients with dementia to be involved in activities and for nursing homes to provide these patients with a variety of activity programs. A tailored intervention program should be designed 
to meet the dementia patient's preferences by securing their emotional immersion and engagement in accordance with their gender and marital status. Also, subsequent studies should also assess other psychosocial variables found to have a key role in activity involvement, such as self-efficacy, perceived social support, motivation, and pleasure.

This study's findings can contribute to the development of programs to decrease the behavioral and psychological symptoms among older people with dementia residing in nursing homes and provide scientific evidence for integrating these activities into long-term services for this population.

Future research should explore valid methods to confirm the preferences of patients with cognitive impairments. As incomplete questionnaires were excluded from the analysis, it will be necessary to investigate the preferred activities of patients with relatively high cognitive levels and high activity, for example, patients with mild cognitive impairment. As reliability between proxy responses and those of patients with dementia were not confirmed, these methodological issues may have affected the interpretation of our data. Additionally, more long-term studies are needed to examine the relationship between these variables because the activity itself may be important, regardless of cognitive function and age (Roberts et al., 2018).

This study has some limitations. As this was a cross-sectional study, prospective studies with larger patient samples that consider various patient subgroups are needed in the future. In addition, we used caregivers' responses for some measures and did not examine actual attendance duration and engagement in activities among patients with dementia. Because our study excluded the participants who did not report preferred activities and those who were diagnosed with other mental disorders, there are limitations regarding generalization to patients with dementia residing in nursing homes.

Nevertheless, we classified the activity preferences of older people with dementia residing in nursing homes using a decision tree and examined their preference levels through logistic regression analysis. Decision trees provided an effective method of decision making because it allowed us to create rules for

\section{REFERENCES}

Ablitt, A., Jones, G. V., and Muers, J. (2009). Living with dementia: a systematic review of the influence of relationship factors. Aging Ment. Health 13, 497-511. doi: 10.1080/13607860902774436

Boyle, G. (2017). Revealing gendered identity and agency in dementia. Health Soc. Care Community 25, 1787-1793. doi: 10.1111/hsc.1 2452

Carstensen, L. L. (2021). Socioemotional selectivity theory: the role of perceived endings in human motivation. Gerontologist 61, 1188-1196. doi: 10.1093/ geront/gnab116

Chatterjee, S., and Hadi, A. S. (2015). Regression Analysis by Example. Hoboken, NJ: John Wiley \& Sons.

Chen, H. T., and Chen, H. T. (2005). Practical Program Evaluation: Assessing and Improving Planning, Implementation, and Effectiveness. Thousand Oaks, CA: Sage Publications.

Chester, H., Clarkson, P., Davies, L., Sutcliffe, C., Davies, S., Feast, A., et al. (2018). People with dementia and carer preferences for home support services in earlystage dementia. Aging Ment. Health 22, 270-279. doi: 10.1080/13607863.2016. 1247424 activity preferences. Thus, information about patients' activity preferences was useful for predicting whether they will commit to an activity and may offer knowledge relevant to providing person-centered care.

\section{DATA AVAILABILITY STATEMENT}

The original contributions presented in the study are included in the article/supplementary material, further inquiries can be directed to the corresponding author.

\section{ETHICS STATEMENT}

The studies involving human participants were reviewed and approved by the Institutional Review Board of Catholic University (MC18QNSI0055). The patients/participants provided their written informed consent to participate in this study.

\section{AUTHOR CONTRIBUTIONS}

J-HK contributed to the conception of the study, interpretation of the data, and drafted the manuscript. E-YP conducted the statistical analyses and interpreted the data. Both authors read and approved the final manuscript.

\section{FUNDING}

This work was supported by a Korea Research Foundation grant funded by the Korean Government (MOEHRD, Basic Research Promotion Fund; NRF-2017R1E1A1A01075188). The funder had no role in the study design, data collection, data analysis, interpretation of data, presentation of results, or decision to submit for publication.

Cohen-Mansfield, J. (2017). Activity groups for persons with dementia: personal predictors of participation, engagement and mood. Psychiatry Res. 257, 375380. doi: 10.1016/j.psychres.2017.07.045

Cohen-Mansfield, J., Gavendo, R., and Blackburn, E. (2019). Activity preferences of persons with dementia: an examination of reports by formal and informal caregivers. Dementia 18, 2036-2048. doi: 10.1177/1471301217740716

Cohen-Mansfield, J., Hai, T., and Comishen, M. (2017). Group engagement in persons with dementia: the concept and its measurement. Psychiatry Res. 251, 237-243. doi: 10.1016/j.psychres.2017.02.013

Cohen-Mansfield, J., Marx, M. S., Dakheel-Ali, M., Regier, N. G., Thein, K., and Freedman, L. (2010a). Can agitated behavior of nursing home residents with dementia be prevented with the use of standardized stimuli? J. Am. Geriatr. Soc. 58, 1459-1464. doi: 10.1111/j.1532-5415.2010.02951.x

Cohen-Mansfield, J., Marx, M. S., Thein, K., and Dakheel-Ali, M. (2010b). The impact of past and present preferences on stimulus engagement in nursing home residents with dementia. Aging Ment. Health 14, 67-73. doi: 10.1080/ 13607860902845574

Cohen-Mansfield, J., Marx, M. S., Thein, K., and Dakheel-Ali, M. (2011). The impact of stimuli on affect in persons with dementia. J. Clin. Psychiatry 72, 480-486. doi: 10.4088/JCP.09m05694oli 
Cohen-Mansfield, J., Marx, M. S., and Werner, P. (1992). Observational data on time use and behavior problems in the nursing home. J. Appl. Gerontol. 11, 111-121. doi: 10.1177/073346489201100109

Cohen-Mansfield, J., and Werner, P. (1997). Management of verbally disruptive behaviors in nursing home residents. J. Gerontol. A Biol. Sci. Med. Sci. 52, M369-M377. doi: 10.1093/gerona/52a.6.m369

Cruz, J., Marques, A., Barbosa, A., Figueiredo, D., and Sousa, L. X. (2013). Making sense (s) in dementia: a multisensory and motor-based group activity program. Am. J. Alzheimers Dis. Other Demen. 28, 137-146. doi: 10.1177/ 1533317512473194

Daumit, G. L., Goldberg, R. W., Anthony, C., Dickerson, F., Brown, C. H., Kreyenbuhl, J., et al. (2005). Physical activity patterns in adults with severe mental illness. J. Nerv. Ment. Dis. 193, 641-646. doi: 10.1097/01.nmd. 0000180737.85895.60

Delmater, R., and Hancock, M. (2001). Data mining Explained: A Manager's Guide to Customer-Centric Business Intelligence. Oxford: Digital press.

Engelman, K. K., Altus, D. E., and Mathews, R. M. (1999). Increasing engagement in daily activities by older adults with dementia. J. Appl. Behav. Anal. 32, 107-110.

Feliciano, L., Steers, M. E., Elite-Marcandonatou, A., Mclane, M., and Arean, P. A. (2009). Applications of preference assessment procedures in depression and agitation management in elders with dementia. Clin. Gerontol. 32, 239-259. doi: 10.1080/07317110902895226

Ivory, J. D. (2006). Still a man's game: gender representation in online reviews of video games. Mass Commun. Soc. 9, 103-114. doi: 10.1207/s15327825mcs0 901_6

Jøranson, N., Pedersen, I., Rokstad, A. M. M., Aamodt, G., Olsen, C., and Ihlebæk, C. (2016). Group activity with Paro in nursing homes: systematic investigation of behaviors in participants. Int. Psychogeriatr. 28:1345. doi: 10 . $1017 /$ S1041610216000120

Kim, H.-J. (2019). Introduction of non-pharmacological treatment for cognitive preservation in elderly dementia patients. J. Soc. Occup. Ther. Aged Demen. 13, 41-46.

Kim, J., Kang, Y., Hong, S., and Park, S. (eds) (2006). "Extraction of spatial rules using a decision tree method: a case study in urban growth modeling," in Proceedings of the International Conference on Knowledge-Based and Intelligent Information and Engineering Systems (Berlin: Springer).

Kitwood, T. (1997). Dementia Reconsidered: The Person Comes First. London: Open university press.

Kyungsoon Park, Y.-R. P. (2018). Moderating effect of social support on the elderly women's gender-role attitude-depressive symptoms relationship. Korean J. Soc. Welf. Res. 57, 29-56. doi: 10.17997/swry.57.1.2

Lepper, S., Rädke, A., Wehrmann, H., Michalowsky, B., and Hoffmann, W. (2020). Preferences of cognitively impaired patients and patients living with dementia: a systematic review of quantitative patient preference studies. J. Alzheimers Dis. 77, 885-901. doi: 10.3233/JAD-191299

Linden, A., and Yarnold, P. R. (2016). Using data mining techniques to characterize participation in observational studies. J. Eval. Clin. Pract. 22, 839-847. doi: 10.1111/jep. 12515

Lopes, T. S., Afonso, R. M. L. B. M., and Ribeiro, O. M. (2016). A quasiexperimental study of a reminiscence program focused on autobiographical memory in institutionalized older adults with cognitive impairment. Arch. Gerontol. Geriatr. 66, 183-192. doi: 10.1016/j.archger.2016.05.007

Mark, R. E. (2012). Understanding the individual with Alzheimer's disease: can socioemotional selectivity theory guide us? Adv. Alzheimer Dis. 1, 77-86. doi: 10.4236/aad.2012.13010

Mast, B. (2009). Uncertainties in dementia: what do people with dementia experience? Generations 33, 30-36.

McDevitt, J., Snyder, M., Miller, A., and Wilbur, J. (2006). Perceptions of barriers and benefits to physical activity among outpatients in psychiatric rehabilitation. J. Nurs. Scholarsh. 38, 50-55. doi: 10.1111/j.1547-5069.2006.00 077.x

Menne, H. L., Johnson, J. D., Whitlatch, C. J., and Schwartz, S. M. (2012). Activity preferences of persons with dementia. Act. Adapt. Aging 36, 195-213. doi: 10.1080/01924788.2012.696234

Myles, A. J., Feudale, R. N., Liu, Y., Woody, N. A., and Brown, S. D. (2004). An introduction to decision tree modeling. J. Chemom. 18, 275-285.
Nygård, L. (2004). Responses of persons with dementia to challenges in daily activities: a synthesis of findings from empirical studies. Am. J. Occup. Ther. 58, 435-445. doi: 10.5014/ajot.58.4.435

Olsen, C., Pedersen, I., Bergland, A., Enders-Slegers, M.-J., and Ihlebæk, C. (2019). Engagement in elderly persons with dementia attending animal-assisted group activity. Dementia 18, 245-261. doi: 10.1177/1471301216667320

O'Sullivan, G., and Hocking, C. (2013). Translating action research into practice: seeking occupational justice for people with dementia. OTJR (Thorofare N. J.) 33, 168-176. doi: 10.3928/15394492-20130614-05

Park, E.-Y., Park, S.-M., and Kim, J.-H. (2019). Psychometric properties of the geriatric quality of life-dementia in older adults with dementia or mild cognitive impairment living in nursing homes. BMC Geriatr. 19:281. doi: 10.1186/s12877019-1307-8

Peeters, J. M., Van Beek, A. P., Meerveld, J. H., Spreeuwenberg, P. M., and Francke, A. L. (2010). Informal caregivers of persons with dementia, their use of and needs for specific professional support: a survey of the National Dementia Programme. BMC Nurs. 9:9. doi: 10.1186/1472-6955-9-9

Richardson, C. R., Avripas, S. A., Neal, D. L., and Marcus, S. M. (2005a). Increasing lifestyle physical activity in patients with depression or other serious mental illness. J. Psychiatr. Pract. 11, 379-388. doi: 10.1097/00131746-20051100000004

Richardson, C. R., Faulkner, G., McDevitt, J., Skrinar, G. S., Hutchinson, D. S., and Piette, J. D. (2005b). Integrating physical activity into mental health services for persons with serious mental illness. Psychiatr. Serv. 56, 324-331.

Roberts, T. J., Gilmore-Bykovskyi, A., Lor, M., Liebzeit, D., Crnich, C. J., and Saliba, D. (2018). Important care and activity preferences in a nationally representative sample of nursing home residents. J. Am. Med. Dir. Assoc. 19, 25-32. doi: 10.1016/j.jamda.2017.06.028

Song, Y.-Y., and Ying, L. (2015). Decision tree methods: applications for classification and prediction. Shanghai Arch. Psychiatry 27:130. doi: 10.11919/ j.issn.1002-0829.215044

Trost, S. G., Owen, N., Bauman, A. E., Sallis, J. F., and Brown, W. (2002). Correlates of adults' participation in physical activity: review and update. Med. Sci. Sports Exerc. 34, 1996-2001. doi: 10.1097/00005768-200212000-00020

Van Der Roest, H. G., Meiland, F. J., Maroccini, R., Comijs, H. C., Jonker, C., and Dröes, R.-M. (2007). Subjective needs of people with dementia: a review of the literature. Int. Psychogeriatr. 19:559. doi: 10.1017/S1041610206004716

Van Mierlo, L., Van der Roest, H., Meiland, F., and Dröes, R. (2010). Personalized dementia care: proven effectiveness of psychosocial interventions in subgroups. Ageing Res. Rev. 9, 163-183. doi: 10.1016/j.arr.2009.09.002

Van't Leven, N., Van der Ploeg, E., de Lange, J., and Pot, A. M. (2018). Indicators to estimate the appropriateness of activating interventions for people living with dementia and for their informal caregivers. Aging Ment. Health 22, 1416-1423. doi: 10.1080/13607863.2017.1358353

Vikström, S., Josephsson, S., Stigsdotter-Neely, A., and Nygård, L. (2008). Engagement in activities: experiences of persons with dementia and their caregiving spouses. Dementia 7, 251-270.

Vollmer, T. R., Marcus, B. A., and LeBlanc, L. (1994). Treatment of self-injury and hand mouthing following inconclusive functional analyses. J. Appl. Behav. Anal. 27, 331-344. doi: 10.1901/jaba.1994.27-331

Conflict of Interest: The authors declare that the research was conducted in the absence of any commercial or financial relationships that could be construed as a potential conflict of interest.

Publisher's Note: All claims expressed in this article are solely those of the authors and do not necessarily represent those of their affiliated organizations, or those of the publisher, the editors and the reviewers. Any product that may be evaluated in this article, or claim that may be made by its manufacturer, is not guaranteed or endorsed by the publisher.

Copyright (C) 2022 Park and Kim. This is an open-access article distributed under the terms of the Creative Commons Attribution License (CC BY). The use, distribution or reproduction in other forums is permitted, provided the original author(s) and the copyright owner(s) are credited and that the original publication in this journal is cited, in accordance with accepted academic practice. No use, distribution or reproduction is permitted which does not comply with these terms. 